\title{
Study on Cross-Area System Operation Utilizing Pumped-Storage Hydro with Bulk Penetration of PVs
}

\author{
H. Tobita ${ }^{1}$, M. Kato ${ }^{1}$, M. Ono ${ }^{2}$, Y. Onoue ${ }^{2}$ \\ ${ }^{1}$ Department of Electrical and Electronic Engineering, \\ Tokyo Denki University, 5, Senju-Asahi-cho, Adachi-ku, Tokyo, Japan, 120-8551 (Japan) \\ ${ }^{2}$ Chubu Electric Power Co. Inc., 1, Higashi-Shin-machi, Higashi-ku, \\ Nagoya-shi, Aichi, Japan, 461-8680 (Japan)
}

\begin{abstract}
In Japan, PV as renewable energy source (RES) is expanding rapidly. However, if the PV penetration becomes too large, the regulation capability for maintaining the system frequency will be insufficient. Where such a problem arises, cross-area system operation that uses regulation capability of other systems through interconnection lines is being studied. This paper proposes the method of maintaining regulation capability by pumped-storage hydro in other electric power systems through changing the base tie line power flow.
\end{abstract}

\section{Key words}

Cross-area system operation, Base tie line power flow, Photovoltaics, Pumped-storage hydro, Load frequency control, Regulation capability

\section{Introduction}

Recently, interest has increased in photovoltaic (PV) as a clean energy source, and the Japanese government has promoted introduction of PV. In Japan, the penetration of $\mathrm{PV}$ at the end of 2016 reached $40.6 \mathrm{GW}$, which is expected to increase sharply to $71.62 \mathrm{GW}$ which is a growth of about 1.8 times in 10 years $^{(1)}$. If the PV is interconnecting as it is, problems such as surplus power generation during peak PV output, insufficient output change speed of thermal unit may occur. In fact, on sunny days in spring when the demand is low, there are many occurrences in which the PV output occupies the majority of the demand. In Japan, there are many pumped-storage hydropower stations that work like a battery. Therefore the surplus PV output is reserved at pumped-storage hydro by lowering the upper pond water level in advance.

On the other hand, the Japanese electric power system is composed of a longitudinal transmission system unlike meshed power systems as in Europe due to geographical constraints. Each electric power system is basically interconnected with only one tie line route, and the supply and demand unbalance within its own system is adjusted by Tie Line Power Flow Frequency Bias Control (TBC). In 2015, the Organization for Cross-regional Coordination of Transmission Operators (OCCTO) was established, and began cross-area supply and demand adjustment beyond each electric power system. Cross-regional supply and demand regulation utilizes the regulation capability of other systems in case of shortage of self-system regulation capability due to bulk penetration of RES. A method of utilizing the margin capacity of the tie line to transmit constant power to another system has been studied (see Fig.1).

In this study, as a measure to cope with shortage of regulation capability at the time of bulk penetration of $\mathrm{PV}$, a method to secure the regulation capability by changing the base tie line power flow $\left(\mathrm{P}_{0}\right)$ and utilizing the pumped-storage hydro in other systems will be studied.

\section{Proposed Method \\ A. Outline}

It is assumed that surplus power occurres in System A with a large PV interconnection when thermal power units have reached their minimum output limit during PV output peak period. At first surplus power is reserved by pumped-storage hydro in the system. However, when surplus power exceeds the installed capacity of pumpedstorage hydro during PV output peak period, electric power which cannot be consumed (net surplus power) is transmitted to System B through increase of base tie line power flow $\left(\mathrm{P}_{0}\right)$. At this time, since thermal power units in System B may also reach their minimum output limit due to PV output increase in System B, the increase in $\mathrm{P}_{0}$ is absorbed by the pumped-storage hydro through

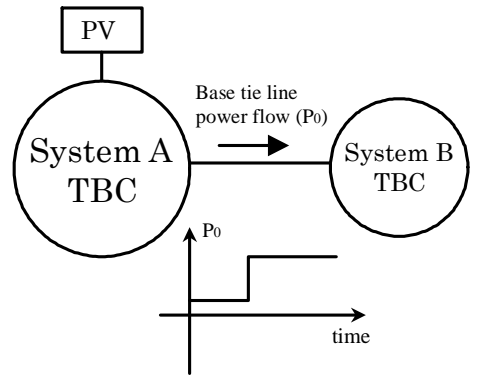

Fig. 1. Base tie line power flow change image 
pumping water up. With System A, it is possible to increase the output of the load frequency control (LFC) unit (thermal power unit) with the increase of $\mathrm{P}_{0}$, and the small regulation capability expands. Therefore, even when a large amount of PV is introduced, the power quality can be maintained without suppressing the PV output.

\section{B. Pumped-Storage Hydro Response}

Here, studied are the methods for suppressing transient frequency fluctuation caused by $\mathrm{P}_{0}$ change and pumping up. Former study ${ }^{(2)}$, assumed that all pumped-storage hydro are variable speed type. In the case of constant speed type, the pumping up quickly reaches the maximum. Therefore, on $\mathrm{P}_{0}$ change, compared are two cases between a variable speed type which is possible to freely change the pumping speed and the time to reach the maximum input, and a constant speed type where the maximum input is reached in a short time.

First, the constant speed type will be explained. In this study, since TBC is assumed in each system, each system adjusts only the supply-demand unbalance $\Delta \mathrm{P}$ in its own system. In the case of the constant speed type, since "power received due to $\mathrm{P}_{0}$ change" and "consumed power by pumping up" is almost the same in System $\mathrm{B}\left(\Delta \mathrm{P}_{\mathrm{B}}\right)$ does not occur. On the other hand, in System $\mathrm{A}, \Delta \mathrm{P}_{\mathrm{A}}$ occurs because the output of the LFC unit cannot follow the sudden $\mathrm{P}_{0}$ change. Therefore, since the sum of $\Delta \mathrm{P}_{\mathrm{A}}$ and $\Delta \mathrm{P}_{\mathrm{B}}$ increases, the frequency fluctuation $\Delta \mathrm{F}$ increases in the constant speed type.

Next, the variable speed type will be explained. Taking into consideration that $\Delta \mathrm{P}$ occurs only in System $\mathrm{A}$ with the constant speed type, the pumping up of System $B$ is delayed and adjusted. By doing this, the sum of $\Delta \mathrm{P}_{\mathrm{B}}$ and already occurred $\Delta \mathrm{P}_{\mathrm{A}}$ approaches 0 , and transient frequency fluctuation can be suppressed.

Since the constant speed type is the main stream, it is desirable to adopt a method presuming that the pumping up will reach the maximum input immediately. Therefore, in order to suppress the transient frequency fluctuation, a method of performing $\mathrm{P}_{0}$ change with a small amount / multiple times is proposed. Transient frequency fluctuation can be suppressed by setting the $\mathrm{P}_{0}$ change amount at one time to a small amount. Here, we are assuming that PV output changes slowly at sunny all day. Thereby, it is possible to maintain the supply-demand balance with a small amount / multiple times of $\mathrm{P}_{0}$ change. On the contrary, for example, when the sky is cloudy and changes suddenly sunny at noon, the PV output suddenly increases. As the required $\mathrm{P}_{0}$ change amount also increases (see Fig.2), the supply-demand balance might be difficult only

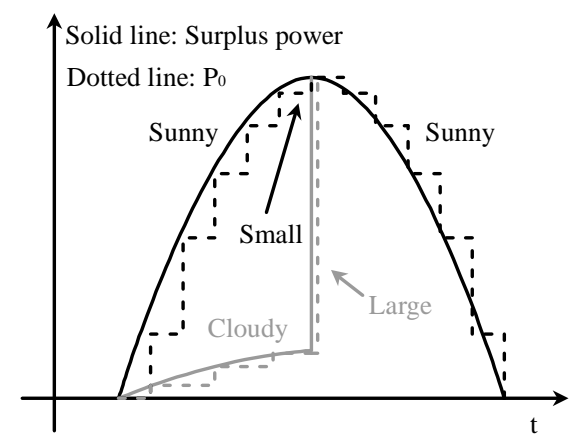

Fig. 2. $\quad P V$ and $P_{0}$ image from cloudy to sunny by a method of making small $\mathrm{P}_{0}$ change amount / multiple times.

\section{C. $\quad P_{0}$ Change Amount}

The appropriate $\mathrm{P}_{0}$ change amount is considered to be such a value that the output of the LFC unit reduced by PV net surplus power to maintain the supply-demand balance can be returned to the initial value each time $\mathrm{P}_{0}$ is changed. In other words, $\mathrm{P}_{0}$ is as same as the net surplus electricity amount. Since $\mathrm{P}_{0}$ change interval is generally 15 minutes, one fourth of net surplus power per hour is appropriate for $\mathrm{P}_{0}$ change amount per one time.

\section{Proposed Method}

Assuming the constant speed type pumped-storage hydro, $\mathrm{P}_{0}$ change method to suppress transient frequency fluctuation is proposed.

\section{Pumping up timing delay}

Pumping up of System B starts at the same time with $\mathrm{P}_{0}$ change. In this case, transient frequency fluctuations become very large because pumping up input reaches the max quickly while LFC units output change speed are relatively low. To suppress frequency fluctuation a method to delay pumping up timing and to adjust LFC unit output is considered. As shown in Fig.3, supply and demand unbalance $\Delta \mathrm{P}$ occurs in each system with $\mathrm{P}_{0}$ change, and an output adjustment signal is sent to each LFC unit ((A) in Fig.3). Apparent demand rapidly increases in System $\mathrm{A}$ due to $\mathrm{P}_{0}$ change. Accordingly, LFC unit increases the output at the maximum output change speed and tries to maintain the supply and demand balance ((B) in Fig.3). The LFC unit, however, can't keep up with sudden change in $\mathrm{P}_{0}$ and the unbalance $\Delta \mathrm{P}_{\mathrm{A}}$ occurs, as well as, $\Delta \mathrm{P}_{\mathrm{B}}$ in System $\mathrm{B}((\mathrm{C})$ in Fig.3). At this time, If the number of commitment units in System A is large, units output can follow the signal quickly, and as a result the frequency gradually rises ((D) in Fig.3). Start timing of pumping-up in System B is decided somewhat before rising. For the constant speed type, it reaches the same amount of input power as $\mathrm{P}_{0}$ change in several ten seconds. As the LFC unit in System $\mathrm{B}$ cannot follow up and $\Delta \mathrm{P}_{\mathrm{B}}$ occurs, the frequency rapidly decreases until reaching the maximum pumping up ((E) in Fig.3). The key point of this proposed method is to raise the frequency by utilizing the difference of the maximum output change speed of LFC units in each system, to start pumping-up at a timing when it rises to a certain extent, and to keep the sudden frequency drop

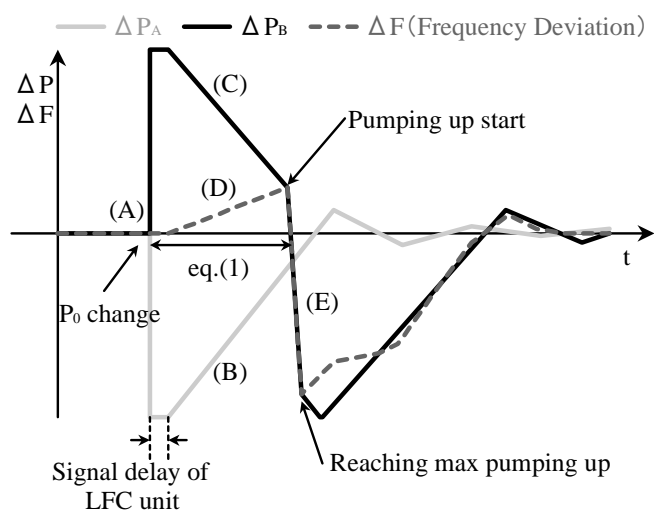

Fig. 3. Image of proposed method 
within the admissible range (e.g. $\pm 0.1 \mathrm{~Hz}$ ).

The pumping start timing $\mathrm{y}[\mathrm{s}]$ that most suppresses the transient frequency fluctuation can be calculated from the relationship of the equation (1) when the $\mathrm{P}_{0}$ change amount is $\mathrm{x}[\mathrm{MW}]$.

$$
y+\frac{\left(\text { Speed }_{A}+{\text { Surplus } \left.- \text { Speed }_{B}\right) \times y}_{\text {Pumped }}\right.}{\text { Pumpen }}
$$

$$
=\text { Signal }+\frac{\mathrm{x}}{\text { Speed }_{\mathrm{A}}+\text { Surplus }}
$$

whre,

- $\mathrm{x}[\mathrm{MW}]: \mathrm{P}_{0}$ change amount

- y [s]: Pumping start timing

- Speed $_{\mathrm{A}}[\mathrm{MW} / \mathrm{s}]$ : Total maximum output change speed of System A

- Speed $_{B}[\mathrm{MW} / \mathrm{s}]$ : Total maximum output change speed of System B

- Surplus [MW/s]: Net surplus power change speed

- Pumped [MW/s]: Pumped-storage hydro pumping up speed

- Signal [s]: LFC signal delay time

If $\Delta \mathrm{P}_{\mathrm{A}}$ is a positive value when the frequency decreases the most, frequency drop can be suppressed. Therefore, the pumping start timing that the Area Control Error (ACE) of each system returns to 0 at the same time can suppress the frequency deviation most. The left side of the equation (1) represents the time until the frequency deviation returns to 0 after $\mathrm{P}_{0}$ change. The right side of the equation (1) represents the time until $\Delta \mathrm{P}_{\mathrm{A}}$ returns to 0 after $\mathrm{P}_{0}$ change.

By using equation (2) in addition to equation (1), it is possible to calculate the maximum $\mathrm{P}_{0}$ amount that falls within the frequency $\pm 0.1 \mathrm{~Hz}$.

$$
\begin{gathered}
\mathrm{x}=\left(\operatorname{Speed}_{\mathrm{A}}+\text { Surplus }- \text { Speed }_{B}\right) \times \mathrm{y}+ \\
\text { Capacity } \times \mathrm{K} \times 100 \times 0.1
\end{gathered}
$$

where,

- Capacity [MW]: Total system capacity $\fallingdotseq$ Total demand

- K [\% MW/Hz]: System constant

Equation (2) represents supply-demand unbalance $\Delta \mathrm{P}$ from the start of pumping up to reaching the maximum input (see Fig.4). When the $\mathrm{P}_{0}$ change amount is $\mathrm{x}$, the pumping up amount is also $\mathrm{x}$. Begining pumping up of $\mathrm{x}$,

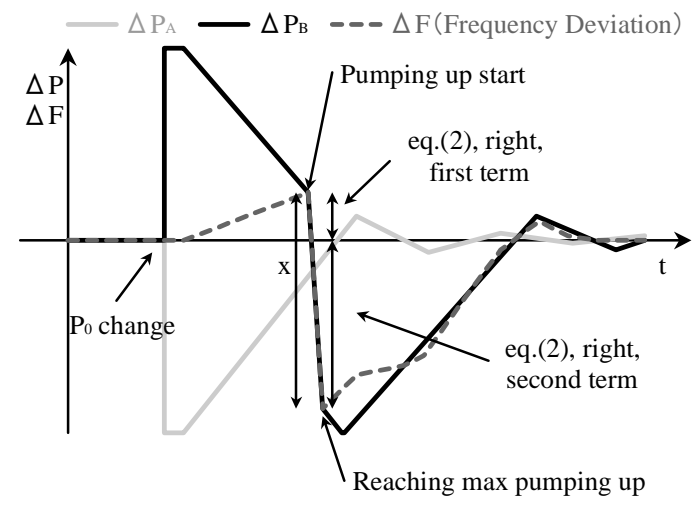

Fig. 4. Image of eq.(2)
$\Delta \mathrm{P}$ becomes $\mathrm{x}$ becouse the LFC unit cannot respond to sudden pumping up. The first term on the right side represents how much $\Delta \mathrm{P}$ changed from the start of $\mathrm{P}_{0}$ change to the start of pumping up. Since it is only necessary to calculate $\Delta \mathrm{P}_{\mathrm{A}}+\Delta \mathrm{P}_{\mathrm{B}}$, it is obtained by the difference of the output change speed of each system. The second term represents $\Delta \mathrm{P}$ at which the frequency deviation maintains within $\pm 0.1 \mathrm{~Hz}$. This can be calculated from the system capacity and the system constant.

\section{Simulation Conditions}

In this study, short-term components of PV output are not taken into consideration in order to compare and investigate methods for suppressing transient frequency fluctuation caused by $\mathrm{P}_{0}$ change and pumping up. In addition, long-term components of demand fluctuation and PV output are not taken into consideration as they have been adjusted by EDC schedule. The simulation time is 1 hour from 12 o'clock which is the PV output peak time (see Table 1). At this time, $\mathrm{P}_{0}$ is changed in the same way as maintaining the supply-demand balance. The net surplus power which cannot be adjusted by EDC is modeled as a ramp function. The simulation software uses MATLAB and Simulink.

\section{A. Target System}

The target system is composed of System A (33134MW) with a large PV introduction amount (31840MW) and System B (14181MW) with a small PV introduction amount (8290MW), interconnected by one tie line.

\section{B. Generation Schedule}

The proposed method is studied under the same conditions as in reference ${ }^{(2)}$. Data such as demand, generation schedule, PV output and the operation method of the LFC unit are used. The installed capacity of the pumped-storage hydro is 9996MW (System A) and 3360MW (System B).

Table 1. Surplus power and net surplus power of peak-time

\begin{tabular}{|c|c|c|c|}
\hline Time[h] & $\begin{array}{c}\text { Surplus power } \\
{[\mathrm{MW}]}\end{array}$ & $\begin{array}{c}\text { Power exceeding } \\
\text { installed capacity of } \\
\text { Pumped-storage[MW] }\end{array}$ & $\begin{array}{c}\text { Difference from } \\
\text { previous time [MW] }\end{array}$ \\
\hline 10 & 9309 & 0 & 0 \\
\hline 11 & 11848 & 1852 & 1852 \\
\hline 12 & 13352 & 3356 & 1504 \\
\hline 13 & 12498 & 2502 & -855 \\
\hline 14 & 10417 & 421 & -2081 \\
\hline
\end{tabular}

Table 2. Maximum output change speed

\begin{tabular}{|c|c|c||c|}
\hline & System A & System B & PV output \\
\hline Oil and LNG-fired [MW/s] & 4.611 & 1.454 & \multirow{2}{*}{0.932} \\
\hline CC [MW/s] & 0.268 & 3.272 & \\
\hline Sum [MW/s] & 4.879 & 4.726 & \\
\hline
\end{tabular}

Table 3. Maximum frequency deviation

\begin{tabular}{|c|c|c|}
\hline $\begin{array}{c}\mathrm{P}_{0} \text { amount } \\
{[\mathrm{MW}]}\end{array}$ & How to change $\mathrm{P}_{0}$ & $\begin{array}{c}\text { Max frequency deviation } \\
{[\mathrm{Hz}]}\end{array}$ \\
\hline 630 & No pumping delay & -0.127 \\
\hline 630 & Proposed method & -0.100 \\
\hline \hline 840 & No pumping delay & -0.171 \\
\hline 840 & Proposed method & -0.138 \\
\hline
\end{tabular}




\section{Simulation}

\section{A. Verification of Pumped-Storage Hydro}

Two cases with both types of the pumped-storage hydro are compared by numerical simulation. Here, while the constant speed type is assumed to reach the maximum pumping up in 1 minute, the variable speed type in 30 minutes. In order to perform this verification, a ramp function of $1500 \mathrm{MW}$ of the net surplus power is input to System A, and the same amount of $1500 \mathrm{MW} \mathrm{P}_{0}$ change is

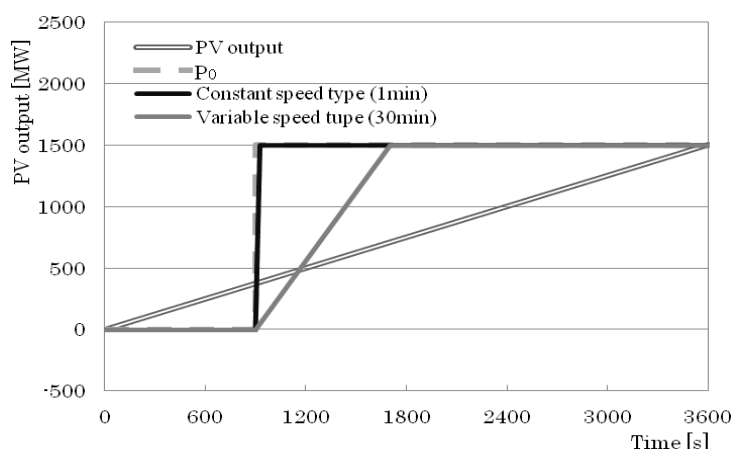

(a) PV output, $\mathrm{P}_{0}$ and Pumping up

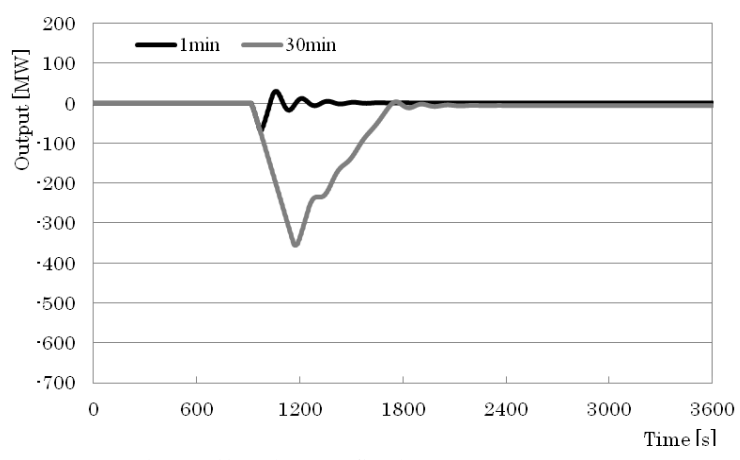

(b) Oil and LNG-fired output (System B)

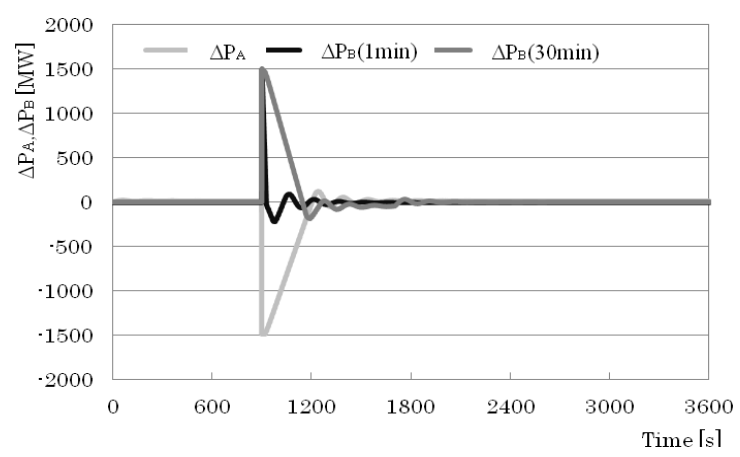

(c) Unbalance in supply and demand within each system

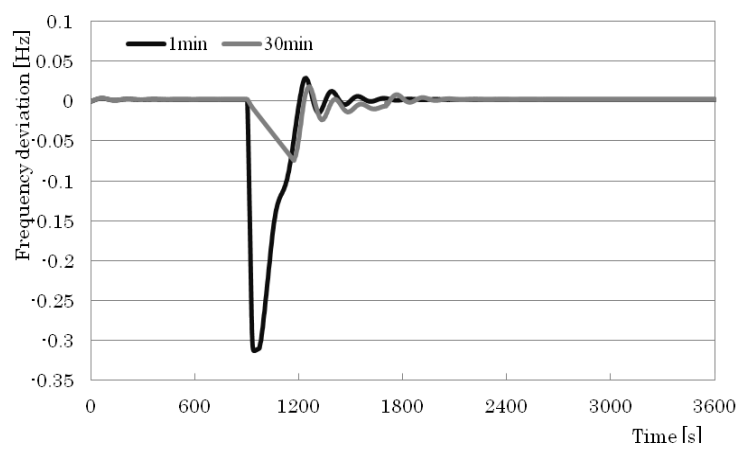

(d) Frequency deviation

Fig. 5. Comparative verification of pumping up type input, both made 15 minutes after the start of the simulation.

\section{B. Simulation Date}

The maximum $\mathrm{P}_{0}$ change amount that can be kept within $\pm 0.1 \mathrm{~Hz}$ is $630 \mathrm{MW}$, after $125 \mathrm{~s}$ from the values caluculated baced on date in Table 2 and equation (1), (2). However, for example, if it is cloudy before noon and becomes sunny at noon where the PV output

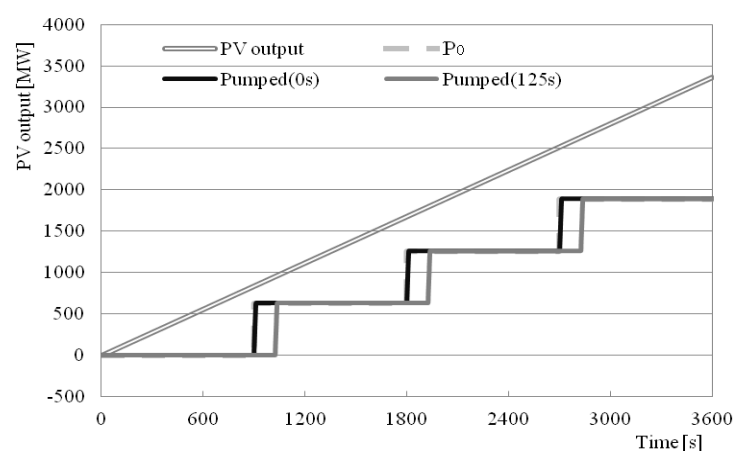

(a) PV output, $\mathrm{P}_{0}$ and Pumping up

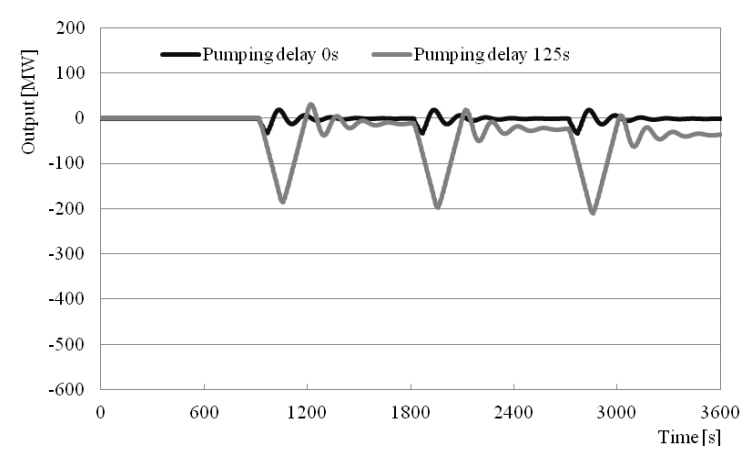

(b) Oil and LNG-fired output (System B)

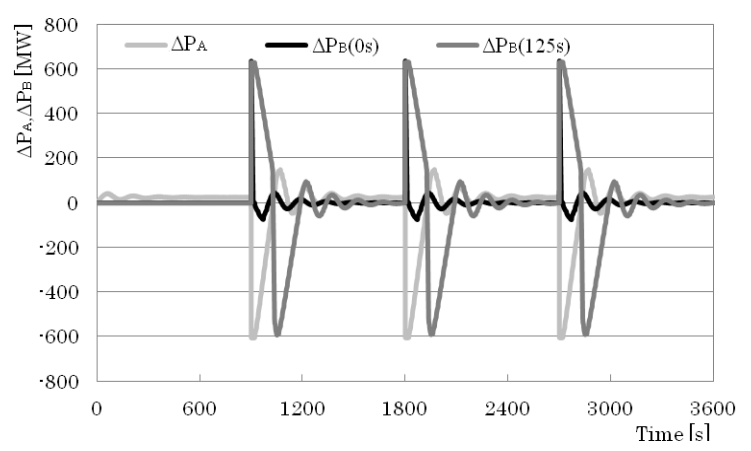

(c) Unbalance in supply and demand within each system

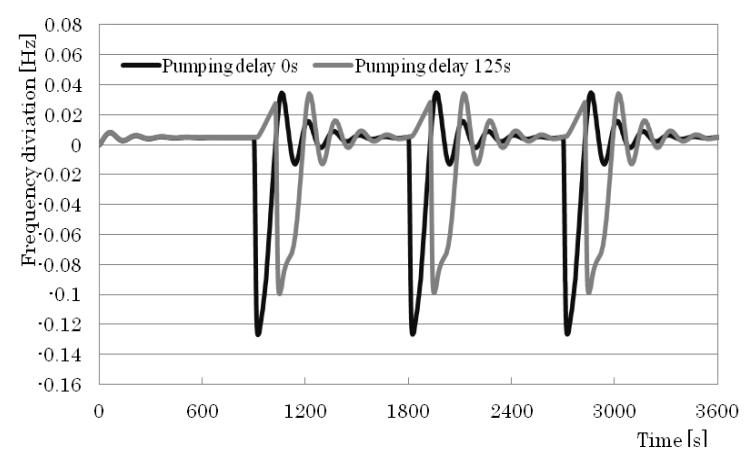

(d) Frequency deviation

Fig. 6. $\mathrm{P}_{0}$ changing amount of $630 \mathrm{MW}$ 
suddenly increases, it is necessary to change $\mathrm{P}_{0}$ at $840 \mathrm{MW}$ $(3356 \mathrm{MW} \div 4)$ every 15 minutes. At this time, the pumping up starts 160 s after the simulation start.

\section{Evaluation Method}

The transient frequency fluctuation with $\mathrm{P}_{0}$ change based on the proposed method is evaluated. Regarding frequency, management target of Japanese power systems is generally $\pm 0.2 \mathrm{~Hz}$ of the power system frequency. In this study within $0.1 \mathrm{~Hz}$ is applied in order to verify the method.

\section{Simulation Results}

Table 3 summarizes the transient maximum frequency deviation when the maximum $\mathrm{P}_{0}$ change amount is 630MW with / without the proposed method. Fig. 5 shows the comparison and verification results with both types of pumped-storage hydro. By pumping up slowly, the thermal unit is responding with the maximum output change speed ((a), (b) in Fig.5). However, since $\mathrm{P}_{0}$ change amount is large, $\Delta \mathrm{P}_{\mathrm{B}}$ is occurred ((c) in Fig.5). By pumping up of the variable speed type, the sum of $\Delta \mathrm{P}_{\mathrm{A}}$ and $\Delta \mathrm{P}_{\mathrm{B}}$ approaches 0 , and transient frequency deviation can be suppressed ((d) in Fig.5).

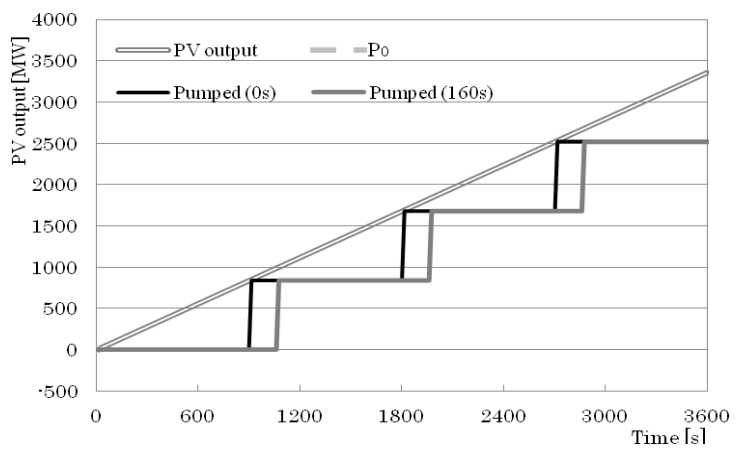

(a) PV output, $\mathrm{P}_{0}$ and Pumping up

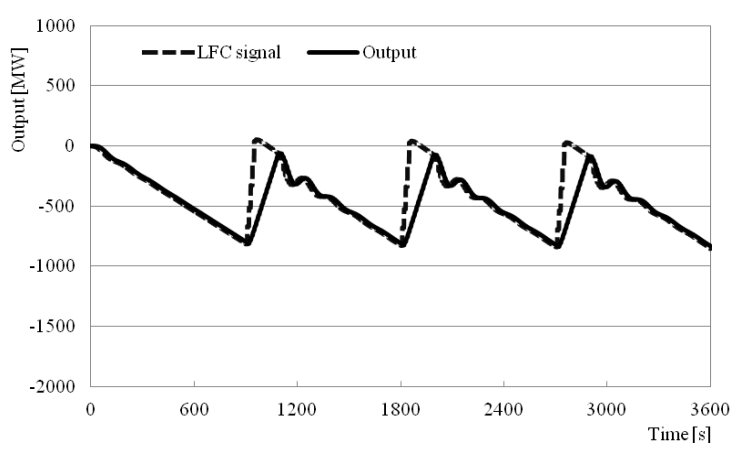

(b) Oil and LNG-fired output (System A)

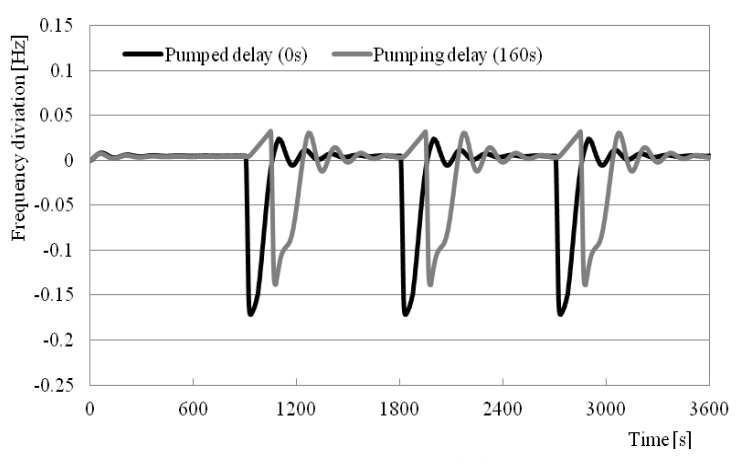

(c) Frequency deviation
Fig.6 shows that the pumping up timing is delayed $125 \mathrm{~s}$ by the proposed method ((a) in Fig.6). If pumping delay is made, the LFC unit reduces the output at the maximum output change speed and respond with it, and the unbalance appears as large as $\Delta \mathrm{P}_{\mathrm{B}}((\mathrm{b})$, (c) in Fig.6). Since the output adjustment speed of System A is higher, the frequency gradually rises until the pumping up is started ((d) in Fig.6). Although the frequency greatly decreases with pumping start, it is within $-0.1 \mathrm{~Hz}$ with almost no error.

Fig.7 shows the result of applying the proposed method at an appropriate $\mathrm{P}_{0}$ change amount of $840 \mathrm{MW}$ with pumping delay. The LFC unit in System A can maintain almost the same regulation capability as the initial value ((b) in Fig.7). Also, although the pumping up amount to be changed at one time is large, by using the proposed method, the transient frequency deviation can be effectively suppressed as compared with the case where pumping delay is not performed ((c) in Fig.7).

\section{Consideration}

By the simulation so far, it was confirmed that the power quality can be maintained by using $\mathrm{P}_{0}$ change and pumped-storage hydro during PV output peak. Only in the daytime operation, however, the capacity ratio of the upper pond in System A exceeds $90 \%$. It is possible to lower the upper pond water level by generation from early evening when the PV output decreases. Considering the storage efficiency of pumped-storage hydro, $70 \%$, Fig.8 shows that it is possible to lower the upper pond water level from almost the full level in the day time by generation during night time, and the consecutive operation is possible on the next day. In addition, due to bulk penetration of $\mathrm{PV}$, there is a concern about socalled "duck curve" due to lack of LFC unit in the early evening. Pumped-hydro generation can relive the output

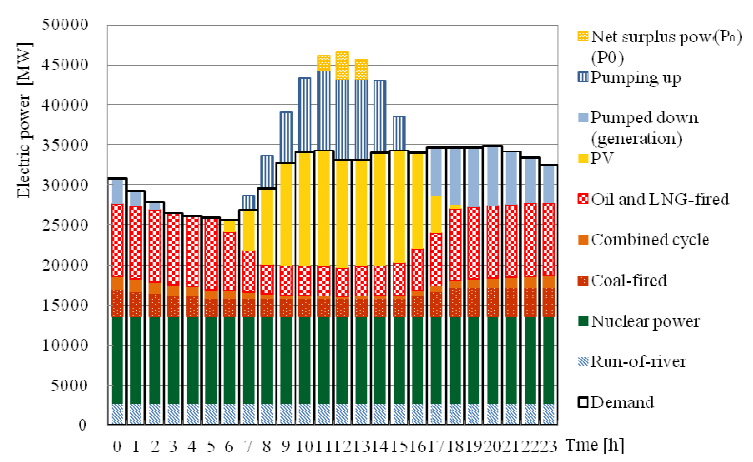

Fig. 8. Generation scheduling of System A (Nuclear Power 33\%)

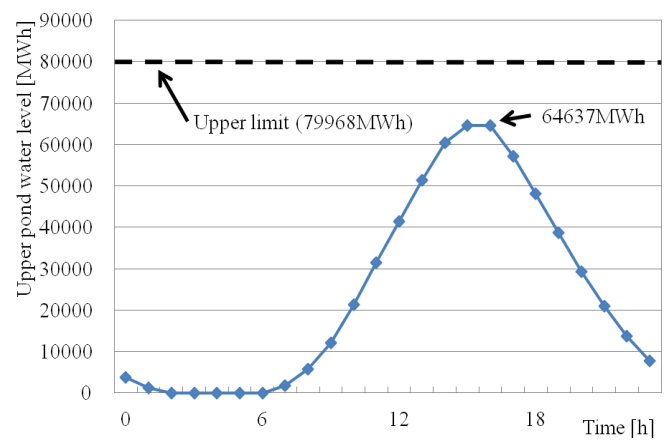

Fig. 9. Changing of upper pond water level of System A

Fig. 7. Results of the proposed method 
sudden increase of the LFC unit and stable operation is possible. Fig.9 shows upper pond water level of System A. It is shown that it is possible to almost empty the upper pond water level during one day operation. If it is expected that the PV output will increase due to the sunny weather forecast, it is necessary to make the pond near empty at the dawn.

In the future power system, it is assumed that nuclear power plant will run as much as before. In other words, it is considered that spring holiday with low demand is a severe case where excess power supply of daytime occurs due to bulk penetration of PV. However, when the base power supply ratio including nuclear power plant is high, Fig. 8 shows that the duck curve problem as described above does not occur. On the other hand, Fig.10 shows daily generation schedule without nuclear power plant. This shows that little surplus power in the daytime occurs and PV output can be effectively utilized. However, because the amount of pumping up power is small and pumped-hydro generation cannot be effectively used early evening, thermal unit output increases rapidly. Fig.11 shows the commitment ratio of oil and LNG-fire unit corresponding to the ratio of nuclear power plant. It means that when the nuclear power plant ratio becomes low, oil and LNG-fire will have to start and stop frequently. In other words, it is impossible to satisfy the unit minimum operation/stop time constraints. Base power including nuclear power plant is necessary not only from the economy viewpoint but also in terms of mitigating the duck curve problem. In the case of bulk penetration of $\mathrm{PV}$, the ratio of base power plant should be planned, taking excess supply problem during daytime into consideration.

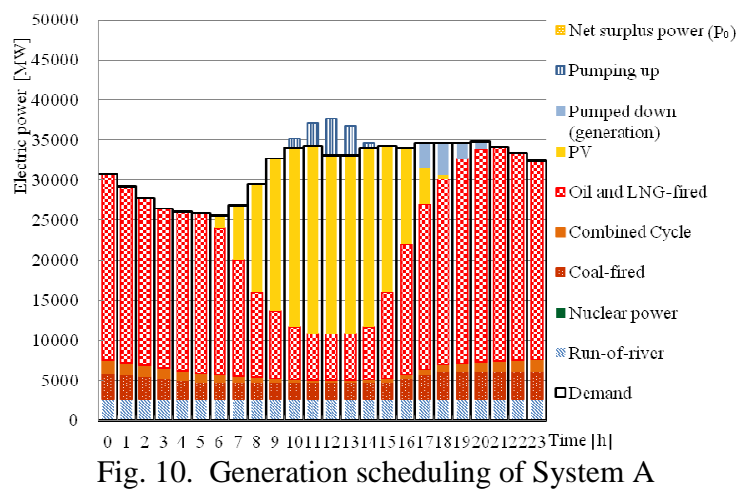

(No Nuclear Power Plant)

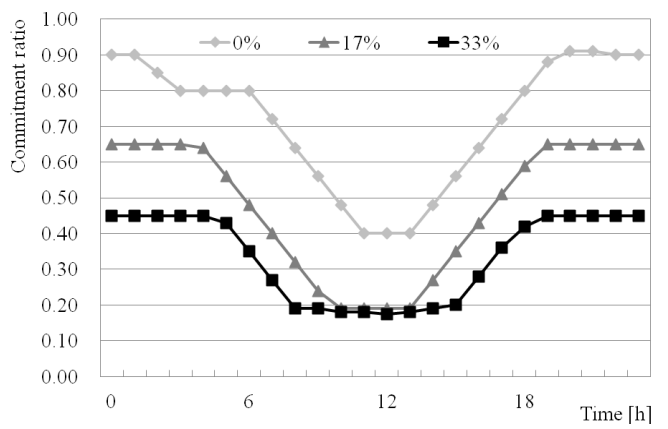

Fig. 11. Commitment ratio of Oil and LNG-fire corresponding to nuclear power ration

\section{Conclusion}

We have proposed a method to secure the regulation capability by pumped-storage hydro of other systems through changing $\mathrm{P}_{0}$. Pumped-storage hydro is assumed not only for variable speed type, but also constant speed type which is generally introduced. As a result of comparative study, the variable speed type is more desirable. In certain cases, however, it has been confirmed that a method of delaying pumping up timing is suitable as well with the constant speed type. By the proposed method, it is possible to maintain power quality without suppressing PV output as much as possible.

In the future, novel method for generation scheduling in consideration with sudden weather change will be necessary. Risk assessment against weather forecast will be required as well.

\section{References}

[1] Organization for Cross-regional Coordination of Transmission Operators,

"Summary of the 2017 supply plan", pp.14-15. https://www.occto.or.jp/pressrelease/2016/files/170330_kyo kyukeikaku_torimatome.pdf (in Japanese)

[2] H. Tobita, M. Kato, M. Ono, Y. Onoue, "Study on CrossArea System Operation by Bulk Penetration of PVs", 2017 Workshop of IEEJ P\&E, 2017 (in Japanese)

[3] J. I. Pérez-Díaz, M. Chazarra, J. García-González, G. Cavazzini, A. Stppato, "Trends and challenges in the operation of pumped-storage hydropower plants", Renewable and Sustainable Energy Reviews, vol. 44, pp. 767-784, 2015.

[4] N. Sakellaridis, J. Mantzaris, G. Tsourakis, C. Vournas, I. Vitellas, "Operation and security assessment of the power system of Crete with integration of pumped storage and concentrated solar thermal plants", 2013 IREP Symposium Bulk Power System Dynamics and Control - IX Optimization, Security and Control of the Emerging Power Grid, pp. 1-12, 2013.

[5] Stefanos V. Papaefthymiou, Eleni G. Karamanou, Stavros A. Papathanassiou, Michael P. Papadopoulos, "A WindHydro-Pumped Storage Station Leading to High RES Penetration in the Autonomous Island System of Ikaria", IEEE Transactions on Sustainable Energy, vol. 1, pp. 163172,2010 